\title{
DIFFUSION MODEL FOR TRANSPORT OF CU(II) IONS THROUGH POLY(4-VINYLPYRIDINE-CO-STYRENE) COATINGS DEPOSITED ON GLASSY CARBON ELECTRODES
}

\author{
NAMAL PRIYANTHA* \\ Department of Chemistry, University of Peradeniya, Peradeniya
}

(Received: 25 January 2001 ; accepted: 11 July 2002)

\begin{abstract}
The electrochemistry of $\mathrm{Cu}$ (II) species at poly(4-vinylpyridine-co-styrene) [PVPCS]-modified glassy carbon electrodes is different from that of the bare electrode. The diffusion barrier created by the PVPCS coating, and the Cu-pyridyl complex formed within the coating are the main contributions for this difference. The apparent diffusion coefficient $\left(\mathrm{D}_{\mathrm{app}}\right)$ of $\mathrm{Cu}(\mathrm{II})$ species through PVPCS coatings, estimated from cyclic voltammetric peak current-potential scan rate relationships, is about an order of magnitude less than that at the bare electrode. The $\mathrm{D}_{\text {app }}$, determined within the concentration range of $3.3 \times 10^{-4} \mathrm{~mol} \mathrm{dm}^{-3}$ and $3.8 \times 10^{-3} \mathrm{~mol} \mathrm{dm}^{-3} \mathrm{Cu}$ (II), can be expressed as $D_{\text {app }}=D_{m}+K / C$, where $D_{m}$ is the diffusion coefficient in the absence of single-file diffusion, $\mathrm{C}$ is the bulk concentration of $\mathrm{Cu}$ (II) species and $\mathrm{K}$ is a function of heterogeneous electron transfer rate constant. The average value of $\mathrm{K}$, obtained for $\mathrm{Cu}(\mathrm{II})+\mathrm{e} \rightleftharpoons \mathrm{Cu}(\mathrm{I})$ process, is $2.5 \times 10^{-20} \mathrm{~mol} \mathrm{~s}^{-1} \mathrm{~m}^{-1}$.
\end{abstract}

Key words: Copper, diffusion, modified electrodes, PVPCS

\section{INTRODUCTION}

The design of chemically modified electrodes is a major breakthrough in the area of electroanalytical chemistry as they overcome many undesirable qualities of bare electrodes. ${ }^{1-3}$ The progress of modified electrodes was further expanded after the development of polymer coated electrodes. Such electrodes have found a variety of applications in electrocatalysis, electroanalysis and electronic technology, in the recent past. ${ }^{4-7}$

The mechanism of electron transfer or ion transfer at the electrode surface covered with a coating is very complex. ${ }^{8-10}$ In general, there are four major modes of reaction of electroactive species at coated electrodes. ${ }^{11}$

Electron or hole conjunction through the coating allowing the electrochemical reaction to occur at the coating-solution interface is the simplest mode. Diffusion of the electroactive species through pores or pinholes in the coating, and through the coating material itself to the electrode surface are two other modes where the reaction occurs at the electrode surface. ${ }^{12}$ The latter case is characterised by two different diffusion coefficients $(D)$ : that of the coating $\left(D_{c}\right)$ and of the electrolyte solution $\left(D_{s}\right)$. This situation is equivalent to the diffusion through two fluid phases with $\mathrm{D}_{\mathrm{c}}<\mathrm{D}_{\mathrm{s}}$.

* Corresponding author 
The difference in diffusion coefficients is obvious, because the coating is more viscous than the electrolyte solution. ${ }^{12}$ The dependence of heterogeneous electron-transfer rate constant on viscosity of coatings has been found to be reciprocal. ${ }^{13}$

The mathematical treatment is very complicated in this situation, since Fick's Laws of Diffusion have to be solved for two phases. The treatment is even more complicated when the partition of electroactive species between the electrolyte solution and the polymer coating is taken into account. Under these circumstances, the concentration profile is shown in Figure 1. Factors such as physical movement of species (physical diffusion), electron self- exchange (electron hopping), morphology of the coating and the counter ion transport are all related to the measured rate of charge transport through a coating deposited on an electrode. ${ }^{14}$ The rate-limiting step thus depends on the particular polymer coating.

The fourth mode, mediated electron-transfer, is possible when the coating itself consists of electroactive moieties, and the potential of the redox centers present in the coating is sufficient to cause an electrochemical reaction of solution species. This concept was used by Dahms ${ }^{15}$ and Ruff ${ }^{16}$, who proposed that the total rate of mass transfer for an electrochemical process at the electrode surface modified with a polymer, that consists of redox centers, has two main contributions: first arising from the physical diffusion and the second due to electron-transfer self-exchange. Since the latter process has also been shown to be equivalent to a diffusion process, the overall rate is described in terms of an apparent diffusion coefficient., 817

The treatment stated above may be applied for a polymer-coated electrode if the coating consists of redox sites. On the other hand, the voltammetric theory has been extended to inert, permeable coatings deposited on electrodes. ${ }^{18}$ As such coatings are regarded as chemically inert and insulating, they modify only the diffusion conditions of species arriving at the electrode surface, and consequently, partition can be neglected.

The objective of this study is to formulate a diffusion model for glassy carbon electrodes coated with poly(4-vinylpyridine-co-styrene) [PVPCS], which neither consists of redox centers, nor is inert in nature. As the polymer, PVPCS, consists of pyridyl ligands, it has a tendency to form complexes with electroactive species in solution. Such polymer-coated electrodes have already found many applications in electroanalytical chemistry, ${ }^{19}$ despite the lack of understanding of the mode of diffusion.

\section{METHODS AND MATERIALS}

Materials: Poly(4-vinylpyridine-co-styrene).[PVPCS], styrene content 10\% (Aldrich), and hexadecylmethane sulfonate [HDMS] (Aldrich) were used for the preparation of polymer coatings. All solutions were prepared with analytical grade $\mathrm{CuCl}_{2}$ in 
deionized water that had been freshly distilled over alkaline $\mathrm{KMnO}_{4}$. De-aeration was accomplished by spraying with $\mathrm{N}_{2}$ for 30 minutes before electrochemical measurements.

Instrumentation: A saturated calomel electrode (SCE) (Fisher Scientific Company, USA), a glassy carbon (GC) disk (Bioanalytical Systems, USA) and a Pt wire were used as reference, working and counter electrodes, respectively. The salt bridge of the reference electrode was filled with a solution of saturated $\mathrm{KCl}$. All potentials were reported with respect to SCE. Before electrochemical measurements, GC surfaces were polished with diamond paste, sonicated for about five minutes, and rinsed thoroughly with water. As needed, electrode surfaces were coated with substrates after this pretreatment.

Cyclic voltammetry was performed in an IBM electrochemical cell with an EC/225 voltammetric analyzer (IBM Instruments, Inc.) and recorded on a Houston Instruments model $200 \mathrm{X}-\mathrm{Y}$ recorder.

Preparation of coated electrodes: The polymer coating solution was prepared by dissolving a mixture of $2.5 \mathrm{mg}$ PVPCS and $6.3 \mathrm{mg} \mathrm{HDMS}$ (stabilizer) in $1.0 \mathrm{~cm}^{3}$ of distilled tetrahydrofuran. A drop of this solution was placed on the surface of well-polished electrodes, and the solvent was allowed to evaporate.

Polymer-coated electrodes were soaked in distilled, deionized water for several hours before electrochemical experiments, to reduce the 'break-in' period of coated electrodes. The average thickness of a polymer-coated electrode was estimated to be $3 \mu \mathrm{m}$ from geometric and volumetric considerations.

Research design: For concentration dependence experiments, $0.05 \mathrm{~cm}^{3}$ aliquots of $0.10 \mathrm{~mol} \mathrm{dm}^{-3} \mathrm{CuCl}_{2}$ analyte solution were added sequentially to the electrochemical cell that contained $30.0 \mathrm{~cm}^{3}$ of $0.1 \mathrm{~mol} \mathrm{dm}^{-3} \mathrm{KCl}$ supporting electrolyte, and the solution was well stirred for complete mixing while $\mathrm{N}_{2}$ was being bubbled. The voltammograms were then recorded in the stable solution. Scan rate dependence experiments were carried out in solutions that had the concentration in the order of $10^{-4} \mathrm{~mol} \mathrm{dm}^{-3}$ to $10^{-3} \mathrm{~mol} \mathrm{dm}^{-3}$ by changing the scan rate from $10 \mathrm{mV} \mathrm{s}^{-1}$ to 500 $\mathrm{mV} \mathrm{s}^{-1}$. Reproducibility of electrochemical measurements was checked by repeating cyclic voltammograms under identical conditions.

\section{RESULTS AND DISCUSSION}

Cyclic voltammetric studies of bare $\mathrm{GC}$ electrodes with sequential additions of $\mathrm{CuCl}_{2}$ showed two reduction peaks associated with $\mathrm{Cu}(\mathrm{II}) / \mathrm{Cu}(\mathrm{I})$ and $\mathrm{Cu}(\mathrm{I}) / \mathrm{Cu}(0)$ couples in the forward potential scan (Figure 2). The first reduction is reversible with a peak separation of about $59 \mathrm{mV}$ at low concentrations; but the latter process is not reversible. During this process, copper is probably deposited as layers on the glassy 


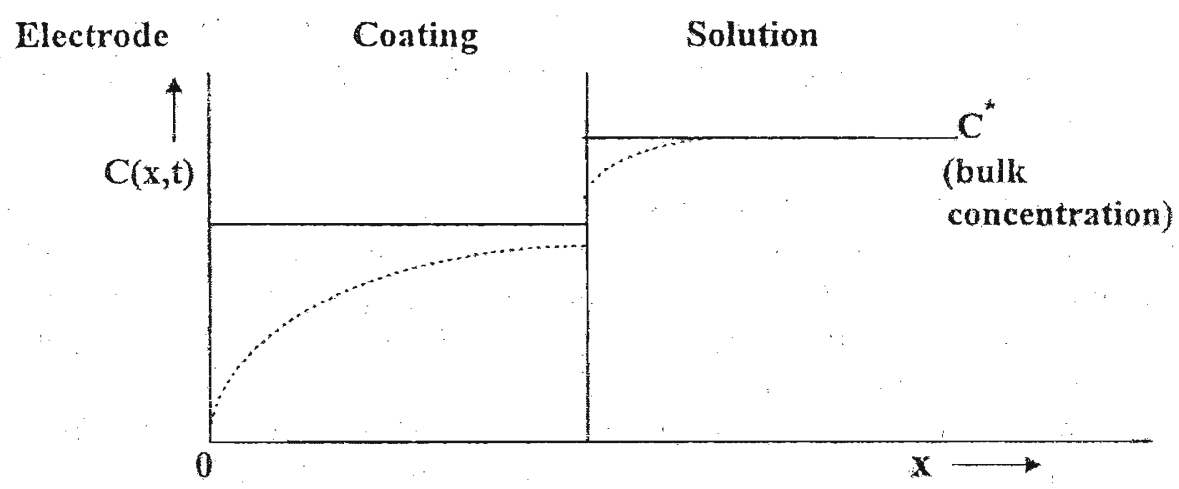

Figure 1: Concentration profile for polymer-coated electrodes: (-) initial profile; (-) profile after application of a potential.

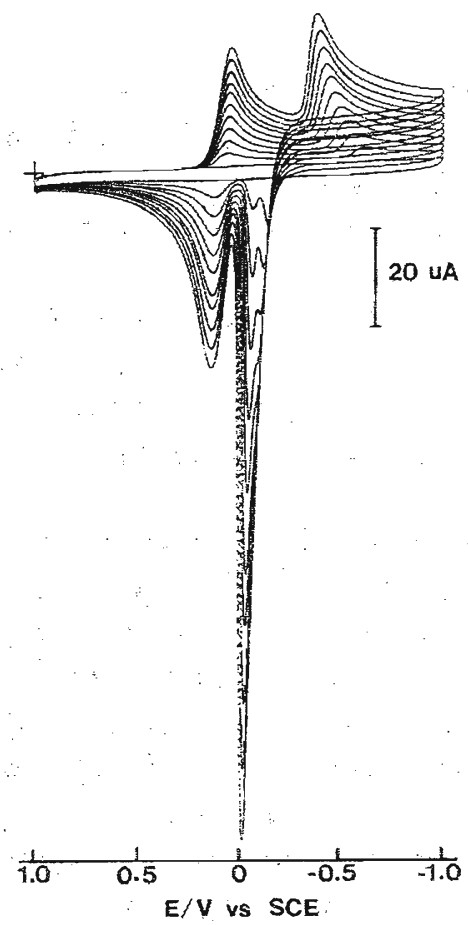

Figure 2: Bare GC response in $0.1 \mathrm{~mol} \mathrm{\textrm {dm } ^ { - 3 }} \mathrm{KCl}$ with sequential additions of $\mathrm{CuCl}_{2}$ solution. Each addition is equivalent to an increase of concentration of $1.67 \times 10^{-4} \mathrm{~mol} \mathrm{dm}^{-3} \mathrm{Cu}$ (II) ions [The flat voltammogram corresponds to the bare GC response, the next one corresponds to a $\mathrm{Cu}$ (II) concentration of $1.67 \times 10^{-4} \mathrm{~mol} \mathrm{dm}^{-3}$, and the last one (top voltammogram) responds to a $\mathrm{Cu}(\mathrm{II})$ concentration of $1.64 \times 10^{-3} \mathrm{~mol} \mathrm{dm}^{-3}$. 
carbon electrode surface, thereby changing the chemical environment of the surface. The peak potential for this reduction process is thus shifted to less negative potentials after each addition. Deposited layers of copper are oxidized back to $\mathrm{Cu}$ (II) in two steps, and the first step itself appears as two voltammetric peaks. It is suggested that the oxidation of the outer layers be easier resulting in the first peak. The second peak of the first step is attributed to the oxidation of deposited $\mathrm{Cu}$ atoms in inner layers, which would have a different chemical environment as compared to that of outer layers. However, the resolution of the two peaks is not apparent at higher concentrations as they are merged when the peaks are large.

The oxidation or the stripping of $\mathrm{Cu}$ would not be completed during the cyclic voltammetric time scale. For this reason, the reduction of $\mathrm{Cu}(\mathrm{I})$ takes place on glassy carbon with a few layers of $\mathrm{Cu}$ deposited on it, which is easier than the reduction of $\mathrm{Cu}(\mathrm{I})$ on pure carbon due to a similar chemical environment. This results in a decrease in the peak potential for the reduction of $\mathrm{Cu}(\mathrm{I})$ at increased concentrations.

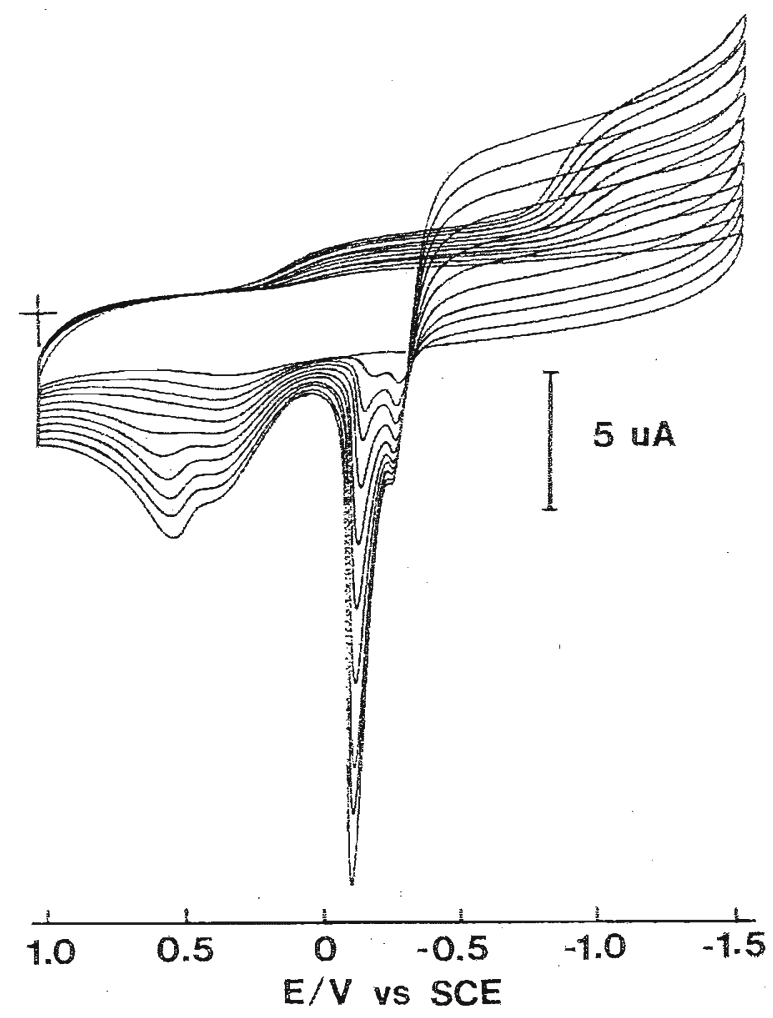

Figure 3: PVPCS-coated GC response in $0.1 \mathrm{~mol} \mathrm{dm}^{-3} \mathrm{KCI}$ with sequential additions of $\mathrm{CuCl}_{2}$ solution. Each addition is equivalent to an increase of concentration of $1.67 \times 10^{-4} \mathrm{~mol} \mathrm{dm}^{-3} \mathrm{Cu}(\mathrm{II})$ ions. 
At the PVPCS-coated electrode, reductions and oxidations resulted in decreased peak currents and broadening of peaks (Figure 3). This is due to the decreased rate of electron transfer, created by the diffusion barrier of PVPCS coatings. Additionally, peak potentials were also altered in the presence of the polymer coating. In addition to the above differences, two combined peaks for the second oxidation process appeared at the coated electrode. It is suggested that the single peak that appeared at low analyte concentrations is due to the oxidation of a $\mathrm{Cu}(\mathrm{I})$-pyridyl complex, which is formed when $\mathrm{Cu}(\mathrm{I})$ ions diffuse through the polymer matrix. Formations of platinum complexes with pyridyl groups, and $\mathrm{Cu}(\mathrm{I})$ complexes with ligands such as sulfonated bathocuprione and 2,9-dimethyl-1,10-phenanthroline at electrode surfaces have already been reported. ${ }^{19,20}$ In addition to the oxidation of $\mathrm{Cu}(\mathrm{I})$-pyridyl complex, free $\mathrm{Cu}(\mathrm{I})$ also diffuses towards the electrode surface for oxidation. This process is significant at high concentrations, and appears at more positive potentials than the oxidation of $\mathrm{Cu}$ of the $\mathrm{Cu}$-pyridyl complex, because it is easier to oxidize complexed $\mathrm{Cu}$ due to the electron donation from the $\mathrm{N}$ atom of pyridyl groups.

From these observations, it is obvious that several factors contribute to the overall diffusion when PVPCS-coated electrodes are in contact with solutions of metal ions. Electron hopping (self-exchange electron-transfer reactions) between the reduced and the oxidized metal ions in the coating, physical displacement (physical diffusion) through the coating, diffusion through channels or pinholes, and electrostatic cross-linking are the main contributions of charge transfer in polymer-modified electrodes. However, the relative importance of these factors is a rather complex issue, and a complete theoretical solution depends on the specific situation.

In order to develop a diffusion model for $\mathrm{Cu}(\mathrm{II}) / \mathrm{Cu}(\mathrm{I})$ species through PVPCS coatings, it is necessary to estimate diffusion coefficients under different conditions. For accurate determinations, scan rate dependence experiments should be conducted within a narrow potential region in which only the $\mathrm{Cu}(\mathrm{II}) / \mathrm{Cu}(\mathrm{I})$ redox process can be monitored according to the equation,

$$
\mathrm{i}_{\mathrm{p}}=\left(2.69 \times 10^{5}\right) \mathrm{n}^{3 / 2} \mathrm{AD}^{1 / 2} \mathrm{v}^{1 / 2} \mathrm{C}^{*}
$$

where $i_{p}$ is the peak current in $A, n$ is the number of electrons associated with the reaction, $A$ is the surface area of the electrode in $\mathrm{cm}^{2}, \mathrm{D}$ is the diffusion coefficient in $\mathrm{cm}^{2} \mathrm{~s}^{-1}, v$ is the potential scan rate in $\mathrm{V} \mathrm{s}^{-1}$ and $\mathrm{C}^{*}$ is the bulk concentration of electroactive species in $\mathrm{mol} \mathrm{cm} \mathrm{cm}^{-3}$, for each concentration. The scan rate was changed from $10 \mathrm{mV} \mathrm{s}^{-1}$ to $500 \mathrm{mV} \mathrm{s}^{-1}$ for each concentration of $\mathrm{Cu}$ (II), within the range of $3.33 \times 10^{-4} \mathrm{~mol} \mathrm{dm}^{-3}$ to $3.85 \times 10^{-3} \mathrm{~mol} \mathrm{dm}^{-3}$. Representative cyclic voltammograms obtained at the lowest concentration at a few scan rates are shown in Figure 4. 


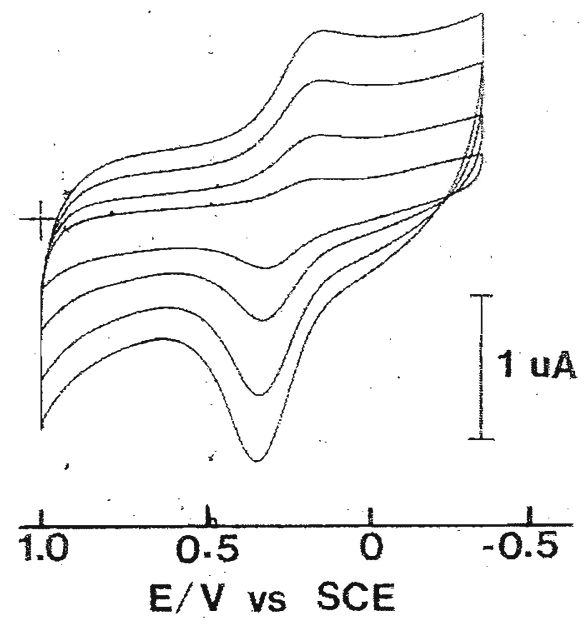

Figure 4: Scan rate dependence of PVPCS-coated GC electrode in $3.32 \times 10^{-4} \mathrm{~mol} \mathrm{dm}^{-3} \mathrm{Cu}$ (II). Supporting electrolyte $0.1 \mathrm{~mol} \mathrm{dm}^{-3} \mathrm{KCl}$. Sample voltammograms shown in the figure were obtained at the scan rates, in $\mathrm{mV} \mathrm{s}^{-1}$, of 10 (lowest voltammogram), 25, 50 and 75 (highest voltammogram).

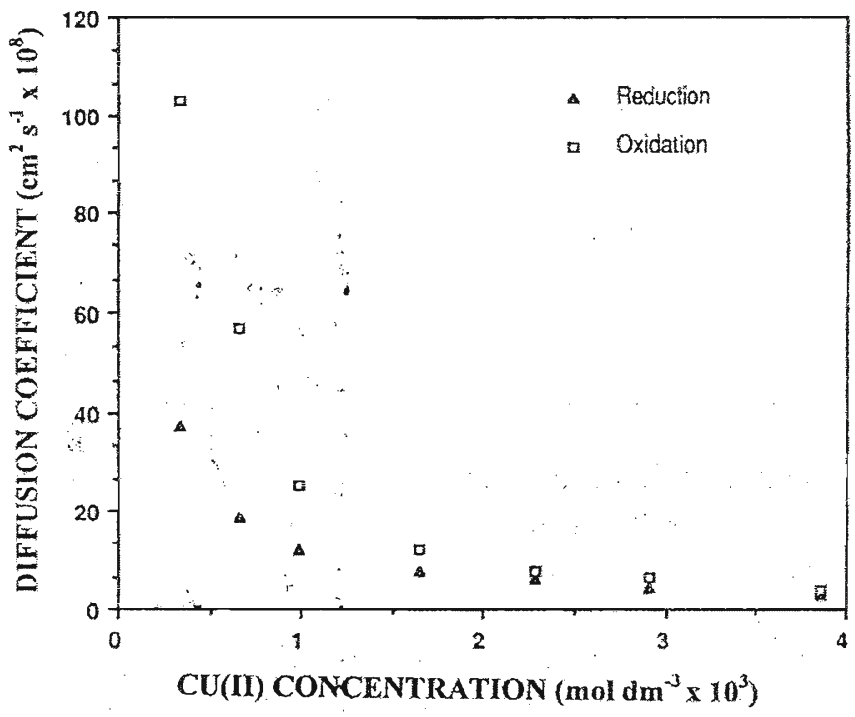

Figure 5: Apparent diffusion coefficients estimated from scan rate dependence experiments for $\mathrm{Cu}(\mathrm{II}) / \mathrm{Cu}$ (I) system. Available scan rates, in $m V s^{-1}, 10,25,50,75,100,200,300,400$ and 500.

Apparent diffusion coefficients calculated from the intercept of $\log i_{p}$ vs. $\log v$ plots, obtained at each concentration according to the linearized form of Equation (1), show a reciprocal relationship with concentration (Figure 5). The average slope 
of these plots within the concentration of $\mathrm{Cu}$ (II) under investigation is approximately 0.7 (Table 1), which indicates that neither the reduction nor the oxidation of copper species at the PVPCS-coated electrode is solely controlled by diffusion. An independent approach for the estimation of apparent diffusion coefficients $\left(D_{\text {app }}\right)$ was made by changing the concentration at a fixed scan rate. The peak currents for the reduction of $\mathrm{Cu}(\mathrm{II})$ and the reoxidation of $\mathrm{Cu}(\mathrm{I})$, estimated from cyclic voltammograms, do not show a linear relationship with concentration (Figure 6). The tangents were drawn at different concentrations, and $\mathrm{D}_{\text {app }}$ was calculated according to the linear relationship between $\log i_{p}$ and $\log C^{*}$ of equation (1). These $D_{\text {app }}$ values also show a reciprocal relationship with concentration.

Table 1: Estimated diffusion coefficients and the slope of $\log i_{p}$ vs. $\log v$ for $\mathrm{Cu}(\mathrm{II})+\mathrm{e} \rightleftharpoons \mathrm{Cu}(\mathrm{I})$ process at the PVPCS coated electrode

\begin{tabular}{ccccc}
\hline Concentration & \multicolumn{2}{c}{ Oxidation process } & \multicolumn{2}{c}{ Reduction process } \\
$10^{-4} \mathrm{~mol} \mathrm{dm}^{-3}$ & $\mathrm{D}_{\text {app }} / 10^{-12} \mathrm{~m}^{2} \mathrm{~s}^{-1}$ & Slope & $\mathrm{D}_{\text {app }} / 10^{-12} \mathrm{~m}^{2} \mathrm{~s}^{-1}$ & Slope \\
\hline 3.33 & 103 & 0.73 & 37.4 & 0.72 \\
6.62 & 57.1 & 0.77 & 18.9 & 0.69 \\
9.94 & 25.3 & 0.66 & 12.1 & 0.65 \\
16.4 & 12.2 & 0.63 & 7.73 & 0.67 \\
22.8 & 7.90 & 0.62 & 6.06 & 0.71 \\
29.1 & 6.40 & 0.61 & 4.47 & 0.66 \\
38.5 & 3.84 & 0.58 & -3.21 & 0.64 \\
average & & 0.66 & & 0.68 \\
\hline
\end{tabular}

Under identical experimental conditions, cyclic voltammetric experiments were carried out with bare glassy carbon electrodes. As expected, peak currents were linearly dependent on the concentration. At higher concentrations of $\mathrm{Cu}(\mathrm{II})$, the oxidation peak current deviated from linearity due to the influence of stripping of $\mathrm{Cu}[\mathrm{Cu} \rightarrow \mathrm{Cu}(\mathrm{I})+\mathrm{e}]$, which had been deposited during the forward potential scan. The linear portions of the plots yielded the concentration independent diffusion coefficients of $7.2 \times 10^{-10}$ and $6.7 \times 10^{-10} \mathrm{~m}^{2} \mathrm{~s}^{-1}$ for the reduction and reoxidation, respectively. The estimated $\mathrm{D}_{\text {app }}$ values for the charge transfer of PVPCS polymer coatings (Table 1 ) were less than that at the bare electrode by an order of magnitude or more, as expected.

The observed reciprocal relationship between $\mathrm{D}_{\text {app }}$ and concentration is not consistent with the Dahms-Ruff model, ${ }^{15,16}$ which explains the behaviour of redox polymer-coated electrodes. According to this model, charge transfer is mainly due to 
electron hopping which makes $\mathrm{D}_{\text {app }}$ increase with concentration. ${ }^{21}$ The decrease in $\mathrm{D}_{\text {app }}$ with concentration in PVPCS polymer coatings is in agreement with nafion coatings with immobilized redox couples..$^{22}$ It is suggested that this decrease be explained by "single-file diffusion" of large $\mathrm{Cu}$ (I)-pyridyl or $\mathrm{Cu}$ (II)-pyridyl complexes, where the movement of diffusing species between the fixed pyridyl sites within the polymer matrix is limited by decreasing the availability of sites as the concentration of the diffusing species increases. For this reason, the factors responsible for increase in diffusion coefficients with concentration such as electron hopping are masked. If the metal-ligand complex is highly charged, electrostatic cross-linking is also responsible for the decrease in $\mathrm{D}_{\mathrm{app}}{ }^{23}$

In addition to single-file diffusion, physical diffusion of uncomplexed $\mathrm{Cu}$ (II)/ $\mathrm{Cu}(\mathrm{I})$ ions is also expected through PVPCS polymer coatings. Therefore, it is proposed that the apparent diffusion coefficient, $\mathrm{D}_{\mathrm{app}}$, be written as

$$
\mathrm{D}_{\mathrm{app}}=\mathrm{D}_{\mathrm{m}}+\mathrm{K} / \mathrm{C}
$$

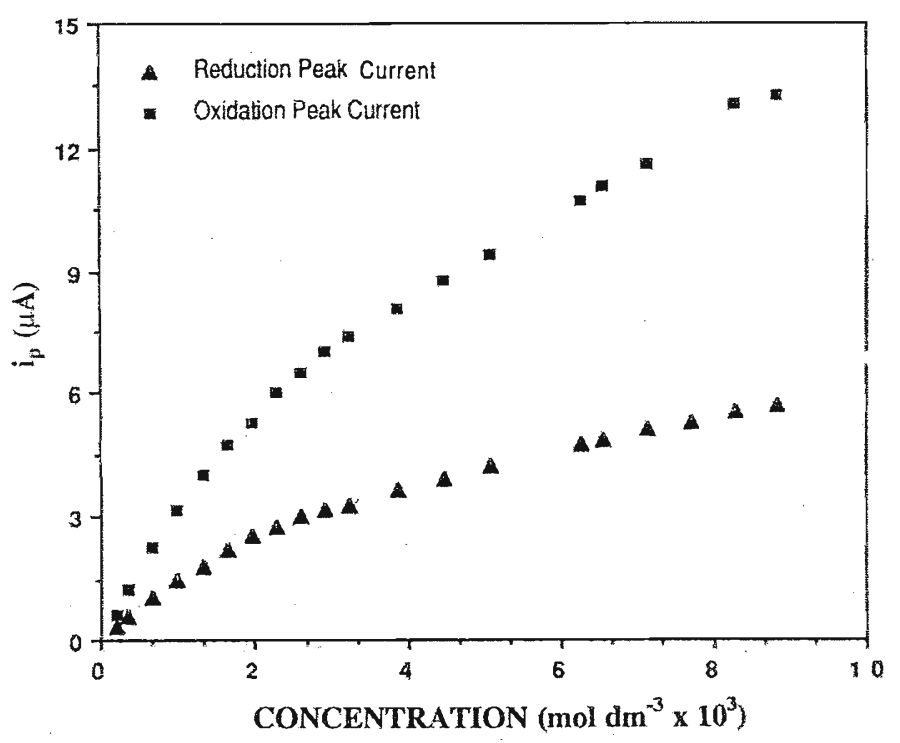

Figure 6: A plot of peak currents estimated from cyclic voltammetric experiments at PVPCS- coated GC electrode vs. $\mathrm{Cu}$ (II) concentration. Scan rate $100 \mathrm{mV} \mathrm{s}^{-1}$.

where $D_{m}$ is the diffusion coefficient in the absence of any single-file and/or electrostatic cross-linking. The term $\mathrm{K}$ is a function of heterogeneous electron transfer rate constant and the coating thickness. It is a constant for a particular coating under a given set of conditions. The validity of the equation was tested by plotting $\mathrm{D}_{\text {app }}$ vs. $1 / \mathrm{C}$ (Figure 7). The constant, $\mathrm{K}$, estimated for the reduction of $\mathrm{Cu}$ (II) and its reoxidation are $1.2 \times 10^{-20} \mathrm{~mol} \mathrm{~s}^{-1} \mathrm{~m}^{-1}$ and $3.8 \times 10^{-20} \mathrm{~mol} \mathrm{~s}^{-1} \mathrm{~m}^{-1}$, respectively. 


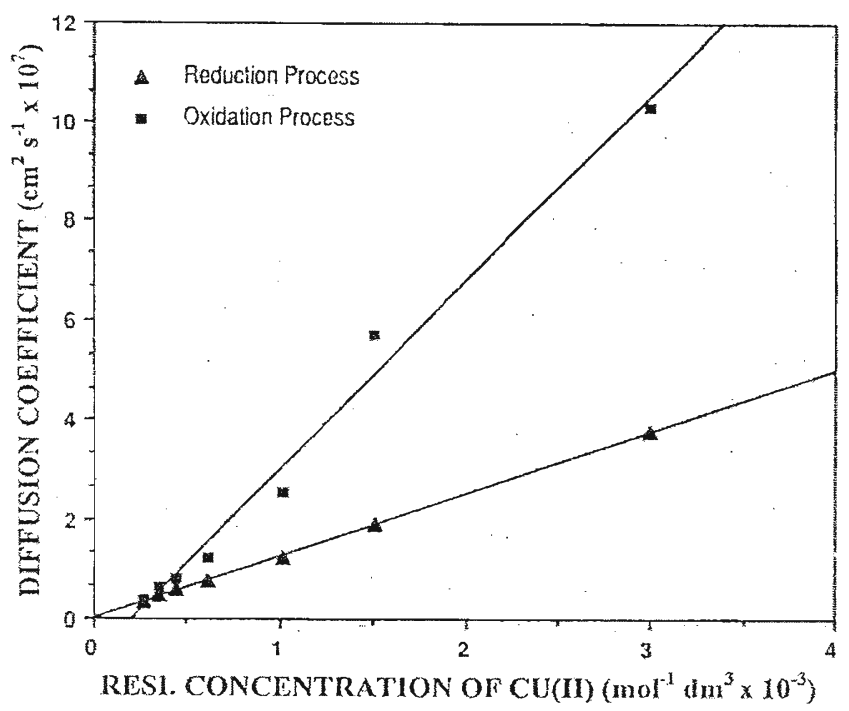

Figure 7: Concentration dependence of the $D_{\text {app }}$, estimated from scan rate dependence measurements, for $\mathrm{Cu}(\mathrm{II}) / \mathrm{Cu}(\mathrm{I})$ system.

\section{References}

1 Smith V.J. (1987). Determination of sulfite using a sulfite oxidase enzyme electrode. Analytical Chemistry 59: 2256-2259.

2 Wang J. \& Golden T. (1989). Metalloporphyrin chemically modified glassy carbon electrodes as catalytic voltammetric sensors. Analytica Chimica Acta 217: $343-351$.

3 Park S.B., Matuszewski W., Meyerhoff M.E., Liu Y.H. \& Kadish K.M. (1991). Potentiometric anion selectivities of polymer membranes doped with indium(III)-porphyrins. Electroanalysis 3: 909-916.

4 Gao Z., Chen B. \& Zi M. (1994). Electrochemistry of ascorbic acid at polypyrrole/ dodecyl sulfate film-coated electrodes and its application. Journal of Electroanalytical Chemistry 365: 197-205.

5 Marques M.R.C. \& Neto G. de O. (1997). Poly(vinylchloride) membrane electrode for the determination of the antibiotic tiamulin. Analytical Sciences 13: $457-461$.

6 Cong H.N., ElAbbassi K. \& Chartier P. (2000). Electrically conductive polymer/ metal oxide composite electrodes for oxygen reduction. Electrochemical and Solid State Letters 3: 192-195. 
7 Belanger D., Ren X.M., Davey J., Uribe F. \& Gottesfeld S. (2000). Characterisation and long-term performance of polyaniline-based electrochemical capacitors. Journal of Electrochemical Society 147: 2923-2929.

8 White H.S., Leddy J. \& Bard A.J. (1982). Polymer films on electrodes. 8. Investigation of charge-transport mechanisms in nafion polymer modified electrodes. Journal of the American Chemical Society 104: 4811-4817.

$9 \quad$ Akande A.B. \& Lowell J. (1987). Charge transfer in metal/polymer contacts. Journal of Physics: Applied Physics 20: 565-578.

10 Neudeck A. \& Dittrich J. (1991). The determination of diffusion coefficients and rate constants from the dependence of the peak separation and peak current on the scan rate of cyclic voltammetry at microcylindrical electrodes. Journal of Electroanalytical Chemistry 313: 37-41.

11 Priyantha N. (1990). Interfacial behaviour and charge transfer reactions at chemically modified electrodes. Ph.D. Dissertation, University of Hawaii. 37-39.

12 Saveant J.M. (1991). Permeation through polymer coatings on electrodes membranes vs. pinhole permeation. Journal of Electroanalytical Chemistry 302: 91-95.

13 Zhang X., Leddy J. \& Bard A.J. (1985). Dependence of rate constants of heterogeneous electron transfer reactions on viscosity. Journal of the American Chemical Society 107: 3719-3721.

14 Guadalupe A.R., Usifer D.A., Potts K.T., Hurrell H.C., Mogstad A.-E. \& Abruna H.D. (1988). Novel chemical pathways and charge-transport dynamics of electrodes modified.with electropolymerized layers of $\left[\mathrm{Co}(\mathrm{v} \text {-terpy })_{2}\right]^{2+}$. Journal of the American Chemical Society 110: 3462-3466.

15 Dahms H. (1968). Electronic conduction in aqueous solution. Journal of Physical Chemistry, 72: 362-364.

16 Ruff I. \& Friedrich V.J. (1971). Transfer diffusion. I. Theoretical. Journal of Physical Chemistry 75: 3297-3302.

17 Martin C.R., Rubinstein I. \& Bard A.J. (1982). Polymer films on electordes.9. Electron and mass transfer in nafion films containing Ru(bpy $)_{3}^{2+}$. Journal of the American Chemical Society 104: 4817-4824. 
18 Delamar M., Pham M.C., Lacaze P.-C. \& Dubois J.-E. (1980). Extension of voltammetric theory to inert, permeable thin-film coated rotating disc electrodes. Part I. General equations of voltammetric curves. Journal of Electroanalytical Chemistry 108: 1-8.

19. Root D.P. \& Priyantha N. (1987). Electroinactive coatings on platinum electrodes in aqueous solution. Journal of Electroanalytical Chemistry 257: 231-237.

20 Prabhu S.V., Baldwin R.P. \& Kryger L. (1987). Chemical preconcentration and determination of copper at a chemically modified carbon paste electrode containing 2;9-dimethyl-1,10-phenanthroline. Analytical Chemistry 59: 1074.

21 Duam P., Lenherd J.R., Rolison D. \& Murray R.M. (1980). Diffusional charge transport through ultrathin films of radiofrequency plasma polymerized vinyl ferrocene at low temperature. Journal of the American Chemical Society 102: 4649-4653.

22 Tsou Y.M. \& Anson F.C. (1985). Charge-transport rates in nafion coatings on electrodes. Surprisingly disparate diffusion coefficients for a single molecule containing two electroactive centers. Journal of Physical Chemistry 89: 38183823.

23 Oyama N. \& Anson F.C. (1980). Catalysis of electrode processes by multiplycharged metal complexes electrostatically bound to polyelectrolyte coatings on graphite electrodes, and the use of polymer-coated rotating disk electrodes in diagnosing kinetic and conduction mechanisms. Analytical Chemistry 52: 1192-1198. 